\title{
Optically Transparent Wood Substrate for Perovskite Solar Cells
}

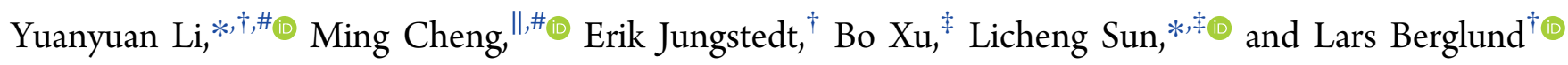

${ }^{\dagger}$ Wallenberg Wood Science Center, Department of Fibre and Polymer Technology, School of Engineering Sciences in Chemistry, Biotechnology and Health (CBH), KTH Royal Institute of Technology, Teknikringen 56-58, SE-100 44 Stockholm, Sweden

"Institute for Energy Research, Jiangsu University, 301 Xuefu Road, Zhenjiang 212013, P. R. China

${ }^{\ddagger}$ Organic Chemistry, Centre of Molecular Devices, Department of Chemistry, School of Engineering Sciences in Chemistry, Biotechnology and Health (CBH), KTH Royal Institute of Technology, Teknikringen 42, SE-100 44 Stockholm, Sweden

Supporting Information

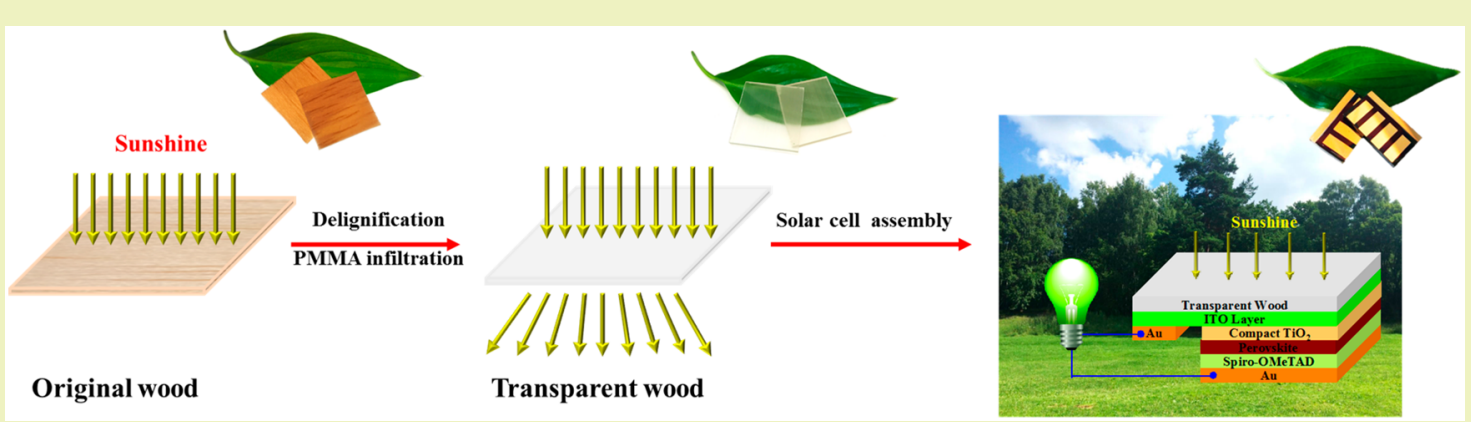

ABSTRACT: Transparent wood is a candidate for use as an energy-saving building material due to its low density (ca. $1.2 \mathrm{~g} /$ $\mathrm{cm}^{3}$ ), high optical transmittance (over $85 \%$ at $1 \mathrm{~mm}$ thickness), low thermal conductivity $\left(0.23 \mathrm{~W} \mathrm{~m}^{-1} \mathrm{~K}^{-1}\right)$, and good loadbearing performance with tough failure behavior (no shattering). High optical transmittance also makes transparent wood a candidate for optoelectronic devices. In this work, for the first time, perovskite solar cells processed at low temperature $(<150$ ${ }^{\circ} \mathrm{C}$ ) were successfully assembled directly on transparent wood substrates. A power conversion efficiency up to $16.8 \%$ was obtained. The technologies demonstrated may pave the way for integration of solar cells with light transmitting wood building structures for energy-saving purposes.

KEYWORDS: Biocomposite, Perovskite solar cell, Energy-Efficient, Building material, Transparent wood, Mechanical properties

\section{INTRODUCTION}

It has been predicted that the energy consumption in the world will increase by $48 \%$ and carbon dioxide emissions by $34 \%$ from 2012 to $2040 .{ }^{1}$ The building sector accounts for over $30 \%$ of the total energy consumption and carbon dioxide emissions, leading to an urgent need for more energy-efficient buildings. ${ }^{2}$ Integration of clean energy technologies with conventional building structures is a promising development. Photovoltaics, which convert solar energy into direct current electricity through semiconducting materials, are becoming increasingly attractive. ${ }^{3}$ Commercial technologies are dominated by crystalline silicon solar cells and thin film solar cells. They are based on high-purity, single-crystalline semiconductors and therefore rely on high-temperature manufacturing processes. Although the price of solar cell-based electricity is dropping, even lower cost and higher power conversion efficiency (PCE) are desirable. Perovskite solar cells (PSCs) have attracted great attention since the first work in 2009 due to the high PCE, easy processability, possible low processing cost, and so on. ${ }^{4,5}$ Even though with the rapid development of PSCs, some challenges still remain such as stability, toxicity, scale-up technologies, and sustainability.
The substrate is a key component for solar cells, which determines the end-use of the products and influences the sustainability of final solar cell products. Glass and plastics are commonly used substrates for solar cells. However, using low cost materials from renewable resources as the substrates is of great interest due to the goal of sustainability. In addition, as a building material, glass shows limitations because of the high brittleness and high thermal conductivity.

Wood is by far the most important structural material from renewable resources, and it is to a large extent used in construction for load-bearing applications. ${ }^{6}$ The potential of using wood as a substrate for functional materials has been discussed in the literature. ${ }^{7-9}$ One limitation for application of wood-based materials in photovoltaics is that wood is not transparent, although wood-based cellulose paper or nanocellulose paper/films have been studied as substrates or functional light management layers in solar cell structures. ${ }^{10,11}$ One reason for low optical transmittance of wood is the light scattering at the interfaces between the cell wall tissue and the

Received: November 29, 2018

Revised: February 11, 2019

Published: February 18, 2019 


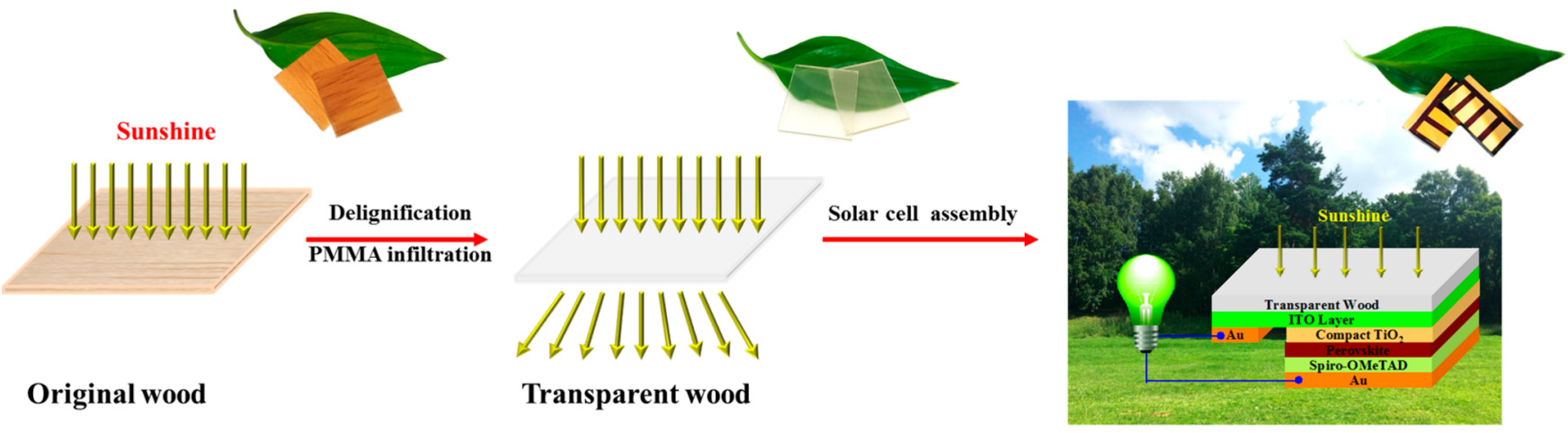

Figure 1. Schematic sketch showing the process of transparent wood preparation and assembling of a solar cell on the transparent wood substrate. The solar cell structure is transparent wood substrate/ITO layer/compact $\mathrm{TiO}_{2}$ /perovskite/spiro-OMeTAD/Au. The yellow arrows represent light. PMMA refers to poly(methyl methacrylate).
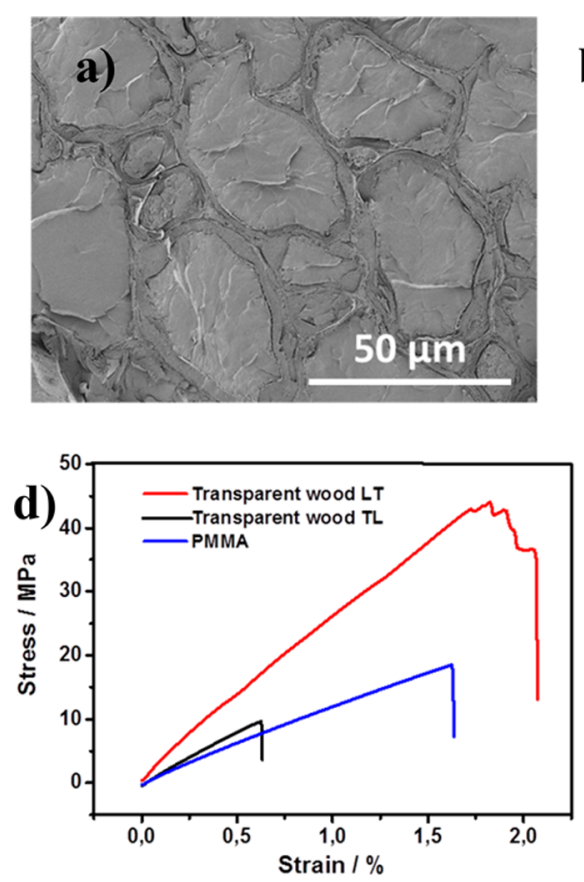
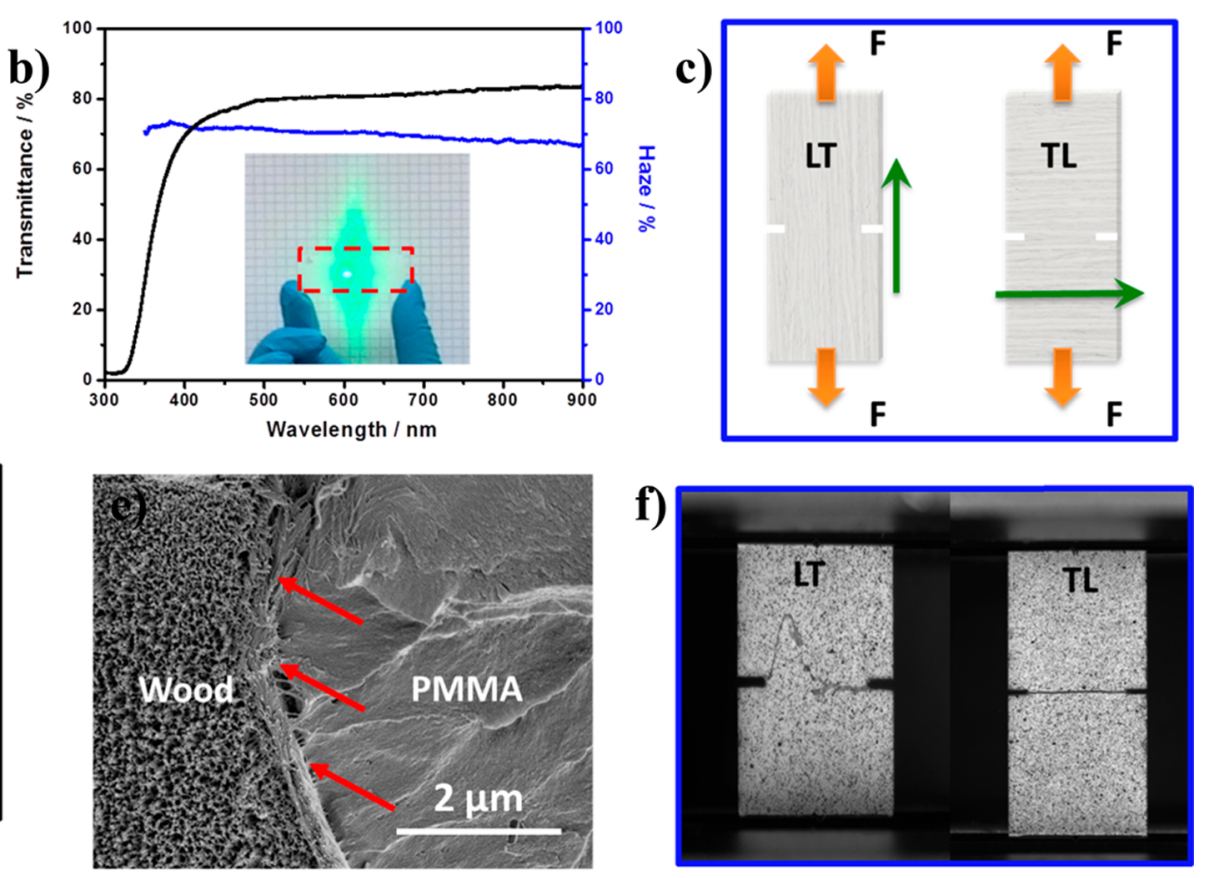

Figure 2. (a) SEM image of transparent wood cross section. (b) Transmittance and haze spectra of transparent wood, specimen thickness 1 mm; inset image is the photo of a green laser beam (diameter of $4 \mathrm{~mm}$ ) scatters as it passes through transparent wood. The dashed line marks the geometry of the transparent wood sample. The size of unit grid is $5 \mathrm{~mm} \times 5 \mathrm{~mm}$. (c) Scheme of transparent wood samples for mechanical test. The orange arrows show the direction of loading force, and the green arrows show the direction of fibers in the transparent wood, $F$ means force/ loading. (d) Stress-strain curves of PMMA, transparent wood TL, and transparent wood LT respectively. (e) SEM image of transparent wood cross section, showing the interface between PMMA and wood. The red arrows point at the interface between wood cell wall and PMMA. (f) Photos of transparent wood after the mechanical test; the left one shows the crack propagation pattern in transparent wood LT, and the right one shows the crack propagation pattern in transparent wood TL.

empty pore space ("lumen") in wood cells (e.g., cells such as tracheids, wood fibers, and vessels). In addition, the presence of strongly light absorbing polymers (mainly lignin) in the cell wall is a problem. ${ }^{12}$ Transparent wood was originally prepared in 1992 for wood morphology studies. ${ }^{13}$ Recently, efforts were developed to combine optical transparency with mechanical performance for light-transmitting, energy-efficient building applications. ${ }^{14-18}$ In recent reviews, the progress of transparent wood technology was discussed in detail. ${ }^{7,9,19}$ Transparent wood exhibits high optical transmittance and haze (over 70\%). The high haze is interesting to be used for light diffusing for solar cells, which is demonstrated by the $\mathrm{Hu}$ group. ${ }^{20}$ However, studies of using transparent wood directly as the substrate for solar cell are rare.
In the present study, transparent wood was for the first time used as the substrate for solar cells. PSCs with PCE up to $16.8 \%$ were prepared directly on transparent wood substrates using a low temperature process $\left(<150^{\circ} \mathrm{C}\right)$. Figure 1 shows a sketch of the transparent wood preparation procedure and the PSC assembly on a transparent wood substrate.

\section{RESULTS AND DISCUSSION}

The lack of transparency in wood is mainly due to the porous lumen space at the center of fibers, tracheids, and vessel cells, with diameters in the order of tens of micrometers. In addition, lignin, tannins, and other phenolic compounds absorb light through chromophoric groups. Lignin is the main component contributing to the brownish wood color. ${ }^{19}$ To make wood 

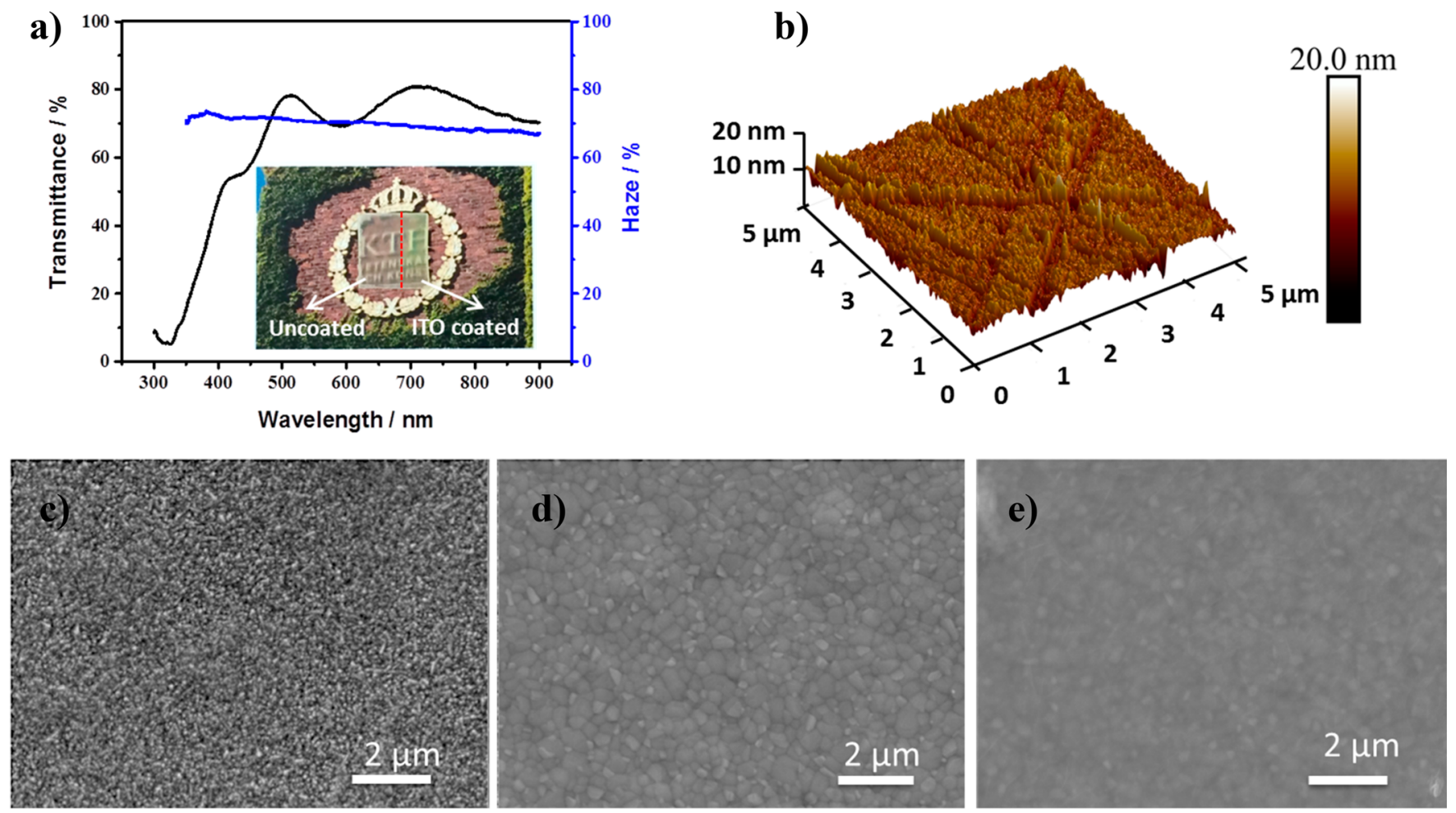

Figure 3. (a) Optical transmittance and haze spectra of transparent wood after ITO coating. Inset image is the transparent without and with ITO coating. (b) AFM image of transparent wood, showing the surface roughness. SEM images of (c) compact $\mathrm{TiO}_{2}$ layer, (d) perovskite layer, and (e) Spiro-OMeTAD coating during solar cell assemble.

transparent, the wood was first delignified with $\mathrm{NaClO}_{2}$ and then infiltrated with a refractive index matched polymer, poly(methyl methacrylate) (PMMA). Figure 2a shows the transparent wood microstructure in cross section, and the lumen pore space is filled by the polymer. In Figure 1, the photo of transparent wood specimens on top of a leaf is shown, demonstrating the optical transparency.

To validate that transparent wood is a suitable substrate for solar cell applications, materials and device characterization was performed. Optical properties were first studied. Figure $2 b$ shows the optical transmittance and haze spectra of transparent wood. A high optical transmittance of $86 \%$ was demonstrated at a wavelength of $550 \mathrm{~nm}$ and a thickness of $1.0 \mathrm{~mm}$, which met the requirements for a substrate for solar cells. At the same time, transparent wood shows a haze of around $70 \%$ in the visible light range. Haze is the ratio between diffused light transmittance to total transmittance (diffused + direct). The haze of $70 \%$ means that diffused transmittance dominates despite high optical transmittance. The inset image in Figure $2 \mathrm{~b}$ demonstrates the light diffusion pattern after the beam has passed through transparent wood. High haze should be favorable for solar cells since the light path in the active layer is increased. This was demonstrated by attaching transparent wood on top of a solar cell, with an improved energy conversion efficiency of $18 \% .^{20}$

Mechanical property is important for solar cell substrates, since it influences the end performance of the device. Mechanical tests were performed in uniaxial tension by control of the displacement rate. Each specimens had $3 \mathrm{~mm}$ deep notches on each side of the specimen edge, double edge notched (DEN). The initial crack was generated by a sharp steel blade. Earlier work on elastic property characterization, rather than toughness, was carried out on transparent wood from balsa. ${ }^{12}$ The fracture toughness has not been studied. The critical stress intensity factor $K_{c}$ (a measure of initiation of crack propagation) at the peak load is a measure of the fracture toughness of the composite. ${ }^{21}$

The critical stress intensity factor $K_{c}$ for DEN specimens was estimated according to eq 1 :

$$
K_{\mathrm{c}}=\sigma_{0} \sqrt{\pi a} f_{4}\left(\frac{a}{w}\right)
$$

where $f_{4}\left(\frac{a}{w}\right)$ is a geometry dependent function. ${ }^{21} \sigma_{0}$ is determined at peak load. Since transparent wood is anisotropic, two different cases are studied as shown in Figure 2c. Loading is applied either parallel to the fiber direction (longitudinal tangential, LT) or perpendicular to fiber direction (tangential longitudinal, TL). Tensile stress-strain curves of notched transparent wood DEN specimens and PMMA are shown in Figure $2 \mathrm{~d}$. The $K_{\mathrm{c}}$ value for PMMA is $1.48 \mathrm{MPa} \mathrm{m} \mathrm{m}^{1 / 2}$, which is comparable with the literature (around 0.9-1.70 MPa m ${ }^{1 / 2}$ ). ${ }^{22}$ Transparent wood LT shows a higher $K_{\mathrm{c}}$ value of $3.2 \mathrm{MPa} \mathrm{m}{ }^{1 / 2}$. This is due to the orientation of the reinforcing wood template skeleton in the composite. Fibers are oriented perpendicular to the plane of the initial crack notch. The wood-PMMA bond integrity appears favorable at the sub-micrometer scale (Figure 2e), which leads to good microscale load transfer in the composites. In addition, the softer biocomposite structure with nanocellulosic cell walls and a polymer matrix phase leads to tougher failure mode compared with glass, which may show brittle fracture (shattering) leading to potential safety problems. Transparent wood TL demonstrates lower initiation $K_{\mathrm{c}}$ value of $0.67 \mathrm{MPa}$ $\mathrm{m}^{1 / 2}$, even lower than that of the neat polymer phase. Figure $2 \mathrm{f}$ shows the crack propagation pattern in transparent wood 

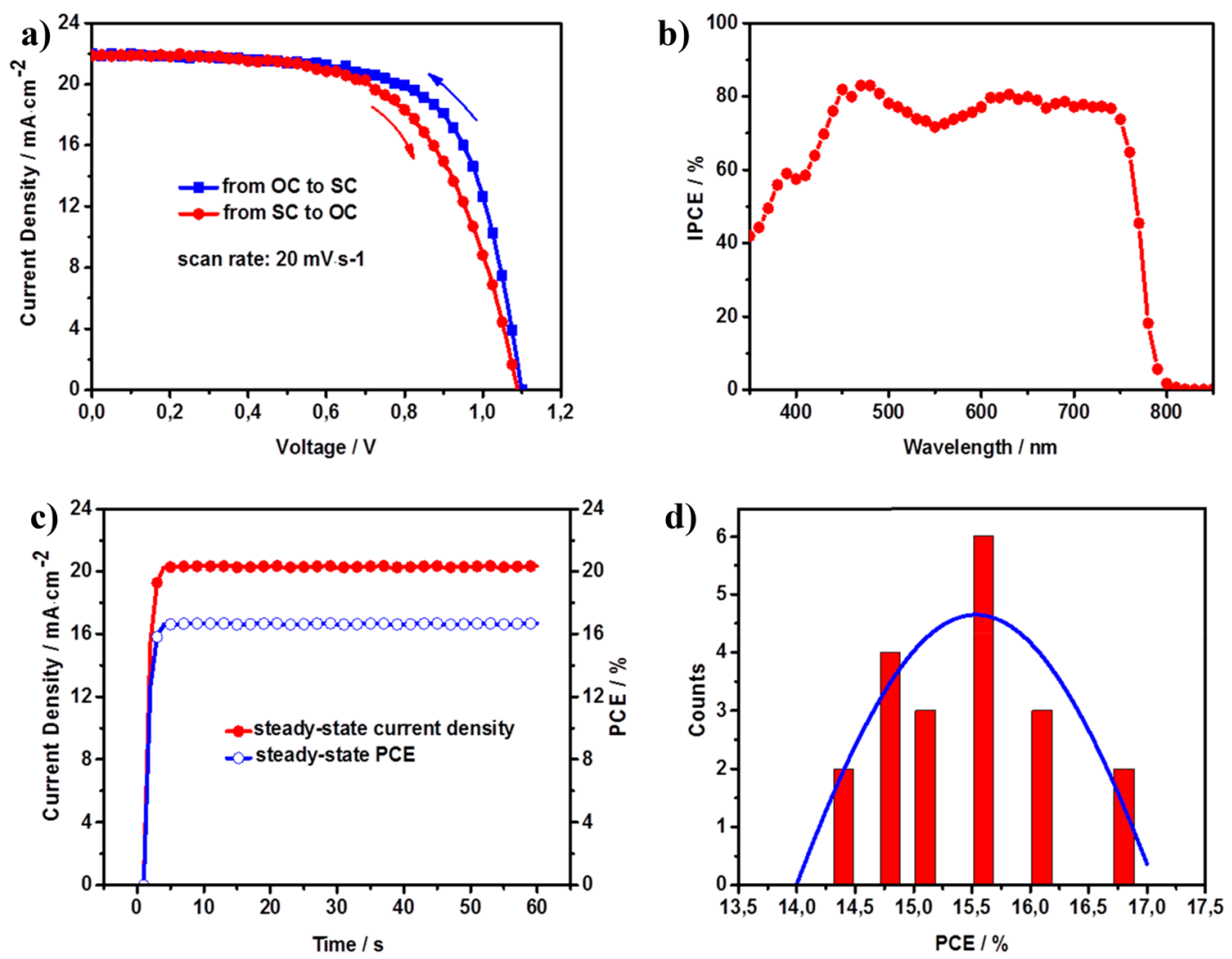

Figure 4. (a) Current density-voltage properties of PSCs (scan rate: $20 \mathrm{mV} / \mathrm{s}$ ). (b) IPCE spectra of PSC. (c) Steady-state current density and PCE at max power output points $(0.82 \mathrm{~V})$. (d) The PCE histogram chart of the devices (a batch of 20 cells).

samples. In transparent wood TL, the crack is progressing straight between the notches following the weakest plane in the biocomposite. For transparent wood LT, the crack most likely started at the notch on the right-hand side and then deviated from the plane perpendicular to the loading direction. The reason is the lower toughness for cracks growing along the fiber direction. Although the fracture toughness $K_{c}$ is lower in the TL direction, the problem can be addressed by lamination of transparent wood layers as in a plywood structure. ${ }^{23}$ In comparison with glass $\left(K_{\mathrm{c}}\right.$ is $0.7-0.85 \mathrm{MPa} \mathrm{m}^{1 / 2}$ for soda-lime glass), ${ }^{24,25}$ transparent wood shows higher fracture toughness. Even in the weakest direction, the fracture toughness of transparent wood is comparable to that of glass.

The toughness criterion provides an argument for transparent wood as a replacement for glass as solar cell substrate. In addition, transparent wood shows much better thermal insulation properties than glass. Transparent wood has a lower thermal conductivity $\left(0.23 \mathrm{~W} \mathrm{~m}^{-1} \mathrm{~K}^{-1}\right)$ than glass $\left(1.0 \mathrm{~W} \mathrm{~m}^{-1}\right.$ $\left.\mathrm{K}^{-1}\right){ }^{26}$ Low thermal conductivity contributes to the energy requirements reduction for air-conditioning systems and lower thermal energy exchange between indoor and outdoor environments. Another strong argument is that wood is from renewable resources and may substantially reduce the carbon footprint associated with building structures. Overall, transparent wood is potentially suitable as a load-bearing substrate for solar cells and shows advantages over glass in energyefficient buildings.

Transparent wood is nonconductive. Therefore, in order to assemble a solar cell on transparent wood, a transparent conductive layer with sufficient conductivity is required. ${ }^{27,28}$ In this work, an indium tin oxide (ITO) film was deposited by pulsed laser deposition. Optical transmittance data showed a decrease due to the deposition of the ITO layer, although there was little in optical haze before and after ITO deposition (Figure 3a). Figure 3a inset image shows that a light green color appears after ITO deposition on transparent wood. The surface roughness of the substrate is important for solar cell assembly. Low surface roughness will increase the conductivity of the coated ITO layer and decrease the risk for pin-holes. The transparent wood substrate described here demonstrated a surface roughness of $30 \mathrm{~nm}$ within the scanning area of $5 \mu \mathrm{m} \times$ $5 \mu \mathrm{m}$. After ITO deposition, the surface roughness changed to a nominal value of $9 \mathrm{~nm}$ (Figure $3 \mathrm{~b}$ ), which is comparable with fluorine doped tin oxide (FIO)-glass that is commonly used for solar cell assembly. A perovskite solar cell was then successfully assembled on the ITO-coated transparent wood. The detailed device structure is transparent wood substrate/ITO/compact $\mathrm{TiO}_{2} /\left(\mathrm{FAPbI}_{3}\right)_{0.85}\left(\mathrm{MAPbBr}_{3}\right)_{0.15} /$ Spiro-OMeTAD $/ \mathrm{Au}$ as shown in Figure 1. In fabricated devices, the compact $\mathrm{TiO}_{2}$ layer $(40-50 \mathrm{~nm}$ thick) functions as electron transport material (ETM), and Spiro-OMeTAD (around $150 \mathrm{~nm}$ thick) functions as hole transport material (HTM). A mixed perovskite $\left(\mathrm{FAPbI}_{3}\right)_{0.85}\left(\mathrm{MAPbBr}_{3}\right)_{0.15}$ (around $450 \mathrm{~nm}$ thick) was used as the light harvesting material. The morphologies of the compact $\mathrm{TiO}_{2}$, perovskite layer, and Spiro-OMeTAD are shown in Figure $3 \mathrm{c}-$ e. A flat dense perovskite film is observed from Figure $3 \mathrm{~d}$. The perovskite film is fully covered by a uniform Spiro-OMeTAD layer (Figure 3e), which is very important for restricting the charge recombination in PSCs. It should be noted that low temperature processing was adapted in order to avoid thermal degradation of the transparent wood substrate. $^{29}$ 
Table 1. Photovoltaic Performance of PSCs Based on Transparent Wood Substrates

\begin{tabular}{ccccccc} 
scan direction & $V_{\mathrm{oc}} / \mathrm{V}$ & $J_{s c} / \mathrm{mA} \cdot \mathrm{cm}^{-2}$ & $\mathrm{FF} / \%$ & $\mathrm{PCE} / \%$ & $\mathrm{hysteresis}$ index $/ \%$ & $R_{\text {sh }} / \Omega \cdot \mathrm{cm}^{2}$ \\
from OC to SC & 1.09 & 21.9 & 70.2 & 16.8 & 0.09 \\
from SC to OC & 1.09 & 21.9 & 66.4 & 15.9 & 4628 \\
\hline
\end{tabular}
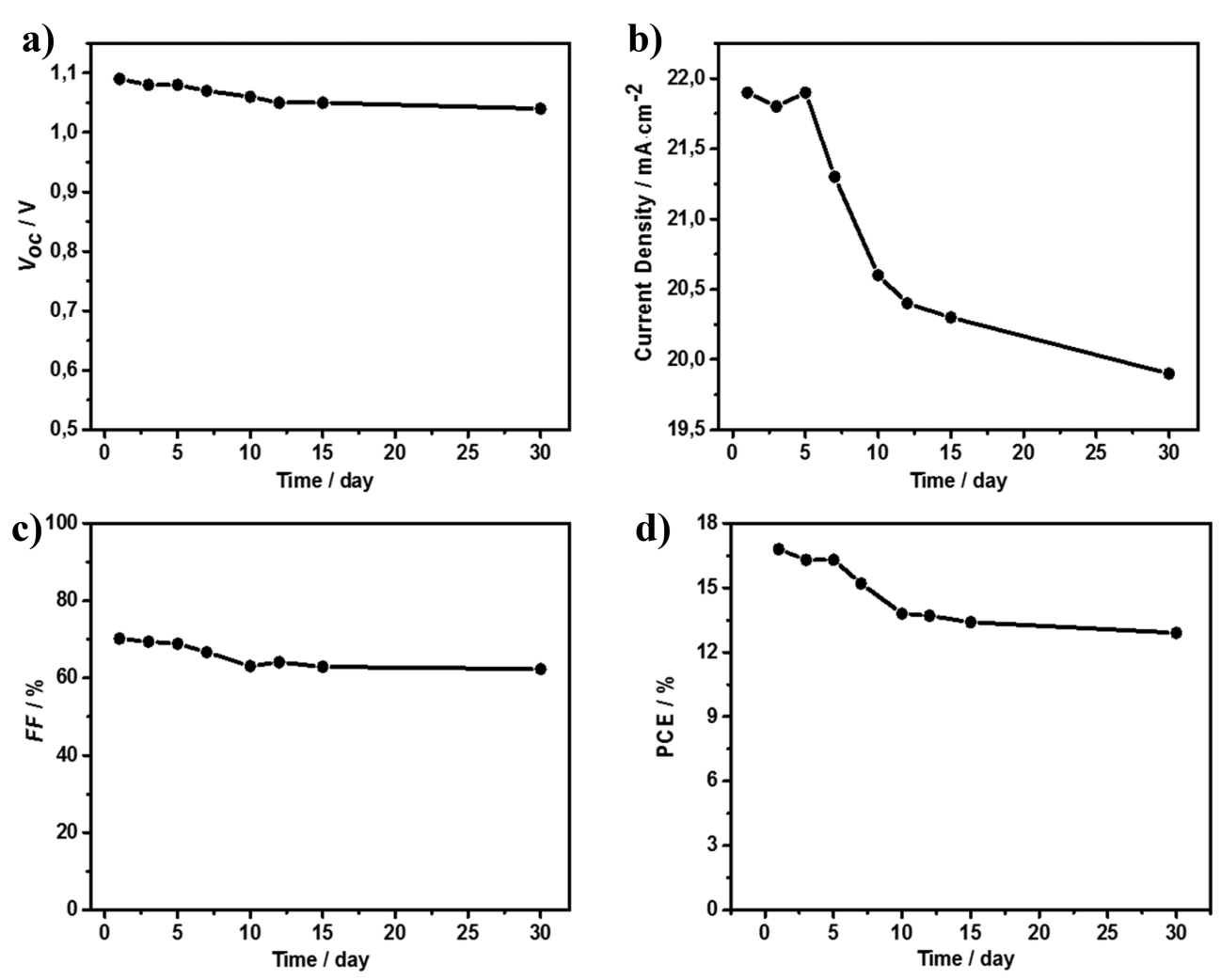

Figure 5. Aging test results: (a) $V_{\mathrm{oc}}$ (b) $J_{\mathrm{sc}}$ (c) FF, and (d) PCE of transparent wood substrate based PSCs.

The photovoltaic performance of transparent wood substrate-based PSC is presented in Figure 4, and the relevant data are collected in Table 1 . The pervoskite-based solar cells on transparent wood substrates exhibited the highest PCE of $16.8 \%$ at $100 \mathrm{~mW} / \mathrm{cm}^{2} \mathrm{AM} 1.5 \mathrm{G}$ simulated irradiation with a short current density $\left(J_{s c}\right)$ of $21.9 \mathrm{~mA} \cdot \mathrm{cm}^{-2}$, an open circuit voltage $\left(V_{\mathrm{oc}}\right)$ of $1.09 \mathrm{~V}$, and a fill factor $(\mathrm{FF})$ of $70.2 \%$ (Figure 4a), which are slightly lower than that of FTO-glass based PSCs (PCE of $18.9 \%, J_{\text {sc }}$ of $24.2 \mathrm{~mA} \cdot \mathrm{cm}^{-2}, V_{\text {oc }}$ of $1.10 \mathrm{~V}$, FF of $71.1 \%$ ) (Figure $S 1$ in Supporting Information). The lower $J_{s c}$ of transparent wood substrate-based PSC can be mainly ascribed to the lower transmittance of conductive transparent wood substrate than that of FTO-glass. The above results indicate that transparent wood could be an interesting candidate for ecofriendly solar cell substrates with a reduced carbon footprint. From the incident-photon-to-current conversion efficiency (IPCE) spectrum (Figure 4b), it can be concluded that PSCs display a very wide photoelectric response to the solar spectrum with a long wavelength limit at around $800 \mathrm{~nm}$, consistent with the band gap of the $\left(\mathrm{FAPbI}_{3}\right)_{0.85}\left(\mathrm{MAPbBr}_{3}\right)_{0.15}$ well. $^{30}$ The steady-state power output characteristic at the maximum power point was further investigated, and the results are shown in Figure 4c. The transparent wood substrate-based PSC showed a steady-state current density of $20.3 \mathrm{~mA} \cdot \mathrm{cm}^{-2}$ and a PCE of $16.6 \%$ under $0.82 \mathrm{~V}$ bias, respectively, matching well with the photocurrent-voltage $(J-V)$ measurement. The histogram chart (Figure $4 \mathrm{~d}$ ) demonstrates a high reproducibility of the devices (a batch of 20 cells). Over $50 \%$ of the manufactured devices obtained a PCE exceeding $15.5 \%$.

Long-term stability is a crucial concern for practical applications of perovskite solar cells. Figure 5 shows the $J_{\text {sc }}$ $V_{\text {oc }}, \mathrm{FF}$, and PCE as a function of time for the transparent wood-based PSCs, in which the devices were kept under air conditions in the dark. It was found that the devices could retain $77 \%$ of its initial performance after $720 \mathrm{~h}$ of aging, showing a good long-term stability.

\section{CONCLUSION}

Transparent wood shows high optical transmittance and haze, good mechanical properties, a smooth surface, and a low thermal conductivity. This makes it suitable as a substrate for solar cell assembly with potential in energy-efficient building applications. For the first time, perovskite solar cells with a power conversion efficiency up to $16.8 \%$ were successfully assembled on optically transparent wood substrates, using a low temperature process below $150{ }^{\circ} \mathrm{C}$. The devices also showed good long-term stability. Our results suggest that transparent wood is a substrate candidate for assembly of sustainable solar cells to replace glass and lower the carbon footprint for the device. Through molecular and nanoscale materials design of the transparent wood substrate, transmittance and haze can be optimized, so that higher solar cell efficiency can be anticipated. 


\section{EXPERIMENTAL SECTION}

All the experimental information is present in the Supporting Information.

\section{ASSOCIATED CONTENT}

\section{S Supporting Information}

The Supporting Information is available free of charge on the ACS Publications website at DOI: 10.1021/acssuschemeng.8b06248.

(PDF)

\section{AUTHOR INFORMATION}

\section{Corresponding Authors}

*(L.S.) E-mail: lichengs@kth.se.

*(Y.L.) E-mail: yua@kth.se.

\section{ORCID $\odot$}

Yuanyuan Li: 0000-0002-1591-5815

Ming Cheng: 0000-0003-0793-0326

Licheng Sun: 0000-0002-4521-2870

Lars Berglund: 0000-0001-5818-2378

\section{Author Contributions}

\#Y.L. and M.C. contributed equally to this work.

\section{Notes}

The authors declare no competing financial interest.

\section{ACKNOWLEDGMENTS}

We acknowledge funding from KTH and European Research Council Advanced Grant (No. 742733) Wood NanoTech, the funding from Knut and Alice Wallenberg foundation through the Wallenberg Wood Science Center at KTH Royal Institute of Technology, and The Swedish Energy Agency and the Swedish Strategic Research Foundation (SSF). Alireza Hajian is acknowledged for the help of taking the AFM image. Min Yan is acknowledged for the support with optical properties measurements.

\section{REFERENCES}

(1) International Energy Outlook 2016, Annual Report; U.S. Energy Information Administration (EIA), 2016; Vol. 0484.

(2) United Nations Environment Programme. Global Status Report 2017 - Towards a Zero-Emission, Efficient, and Resilient Buildings and Construction Sector; 2017.

(3) Xu, B.; Sheibani, E.; Liu, P.; Zhang, J.; Tian, H.; Vlachopoulos, N.; Boschloo, G.; Kloo, L.; Hagfeldt, A.; Sun, L. Carbazole-Based Hole-Transport Materials for Efficient Solid-State Dye-Sensitized Solar Cells and Perovskite Solar Cells. Adv. Mater. 2014, 26 (38), 6629-6634.

(4) Petrus, M. L.; Schlipf, J.; Li, C.; Gujar, T. P.; Giesbrecht, N.; Müller-Buschbaum, P.; Thelakkat, M.; Bein, T.; Hüttner, S.; Docampo, P. Capturing the Sun: A Review of the Challenges and Perspectives of Perovskite Solar Cells. Adv. Energy Mater. 2017, 7 (16), 1700264.

(5) Green, M. A.; Ho-Baillie, A.; Snaith, H. J. The Emergence of Perovskite Solar Cells. Nat. Photonics 2014, 8 (7), 506-514.

(6) Dinwoodie, J. M. Timber: Its Nature and Behaviour Second, Second Edi.; E\&FN SPON, 2000.

(7) Berglund, L. A.; Burgert, I. Bioinspired Wood Nanotechnology for Functional Materials. Adv. Mater. 2018, 30 (19), 1704285.

(8) Burgert, I.; Cabane, E.; Zollfrank, C.; Berglund, L. Bio-Inspired Functional Wood-Based Materials - Hybrids and Replicates. Int. Mater. Rev. 2015, 60 (8), 431-450.
(9) Jiang, F.; Li, T.; Li, Y.; Zhang, Y.; Gong, A.; Dai, J.; Hitz, E.; Luo, W.; Hu, L. Wood-Based Nanotechnologies toward Sustainability. Adv. Mater. 2018, 30 (1), 1703453.

(10) Fang, Z.; Zhu, H.; Yuan, Y.; Ha, D.; Zhu, S.; Preston, C.; Chen, Q.; Li, Y.; Han, X.; Lee, S.; et al. Novel Nanostructured Paper with Ultrahigh Transparency and Ultrahigh Haze for Solar Cells. Nano Lett. 2014, 14 (2), 765-773.

(11) Yao, Y.; Tao, J.; Zou, J.; Zhang, B.; Li, T.; Dai, J.; Zhu, M.; Wang, S.; Fu, K. K.; Henderson, D.; et al. Light Management in Plastic-Paper Hybrid Substrate towards High-Performance Optoelectronics. Energy Environ. Sci. 2016, 9 (7), 2278-2285.

(12) Li, Y.; Fu, Q.; Yang, X.; Berglund, L. A. Transparent Wood for Functional and Structural Applications. Philos. Trans. R. Soc., A 2018, 376 (2112), 20170182.

(13) Fink, S. Transparent Wood - A New Approach in the Functional Study of Wood Structure. Holzforschung 1992, 46 (5), 403-408.

(14) Li, Y.; Fu, Q.; Yu, S.; Yan, M.; Berglund, L. Optically Transparent Wood from a Nanoporous Cellulosic Template: Combining Functional and Structural Performance. Biomacromolecules 2016, 17 (4), 1358-1364.

(15) Zhu, M.; Song, J.; Li, T.; Gong, A.; Wang, Y.; Dai, J.; Yao, Y.; Luo, W.; Henderson, D.; Hu, L. Highly Anisotropic, Highly Transparent Wood Composites. Adv. Mater. 2016, 28 (26), 51815187.

(16) Li, T.; Zhu, M.; Yang, Z.; Song, J.; Dai, J.; Yao, Y.; Luo, W.; Pastel, G.; Yang, B.; Hu, L. Wood Composite as an Energy Efficient Building Material: Guided Sunlight Transmittance and Effective Thermal Insulation. Adv. Energy Mater. 2016, 6 (22), 1601122.

(17) Li, Y.; Yang, X.; Fu, Q.; Rojas, R.; Yan, M.; Berglund, L. A. Towards Centimeter Thick Transparent Wood through Interface Manipulation. J. Mater. Chem. A 2018, 6 (3), 1094-1101.

(18) Yu, Z.; Yao, Y.; Yao, J.; Zhang, L.; Chen, Z.; Gao, Y.; Luo, H. Transparent Wood Containing $\mathrm{Cs}_{\mathrm{x}} \mathrm{WO}_{3}$ Nanoparticles for HeatShielding Window Applications. J. Mater. Chem. A 2017, 5 (13), 6019-6024.

(19) Li, Y.; Vasileva, E.; Sychugov, I.; Popov, S.; Berglund, L. Optically Transparent Wood: Recent Progress, Opportunities, and Challenges. Adv. Opt. Mater. 2018, 6 (14), 1800059.

(20) Zhu, M.; Li, T.; Davis, C. S.; Yao, Y.; Dai, J.; Wang, Y.; AlQatari, F.; Gilman, J. W.; Hu, L. Transparent and Haze Wood Composites for Highly Efficient Broadband Light Management in Solar Cells. Nano Energy 2016, 26, 332-339.

(21) Tada, H.; Paris, P. C.; Irwin, G. R. The Stress Analysis of Cracks Handbook, 2nd ed.; Paris Productions Inc: St. Louis, MI, 1985.

(22) Varela-Rizo, H.; Weisenberger, M.; Bortz, D. R.; MartinGullon, I. Fracture Toughness and Creep Performance of PMMA Composites Containing Micro and Nanosized Carbon Filaments. Compos. Sci. Technol. 2010, 70, 1189-1195.

(23) Fu, Q.; Yan, M.; Jungstedt, E.; Yang, X.; Li, Y.; Berglund, L. A. Transparent Plywood as a Load-Bearing and Luminescent Biocomposite. Compos. Sci. Technol. 2018, 164, 296-303.

(24) Wiederhorn, S. M. Fracture Surface Energy of Glass. J. Am. Ceram. Soc. 1969, 52 (2), 99-105.

(25) Gong, J.; Chen, Y.; Li, C. Statistical Analysis of Fracture Toughness of Soda-Lime Glass Determined by Indentation. J. NonCryst. Solids 2001, 279 (2-3), 219-223.

(26) Li, Y.; Fu, Q.; Rojas, R.; Yan, M.; Lawoko, M.; Berglund, L. Lignin-Retaining Transparent Wood. ChemSusChem 2017, 10 (17) 3445-3451.

(27) Cheng, M.; Li, Y.; Safdari, M.; Chen, C.; Liu, P.; Kloo, L.; Sun, L. Efficient Perovskite Solar Cells Based on a Solution Processable Nickel(II) Phthalocyanine and Vanadium Oxide Integrated Hole Transport Layer. Adv. Energy Mater. 2017, 7 (14), 1602556.

(28) Lang, A. W.; Li, Y.; De Keersmaecker, M.; Shen, D. E.; Österholm, A. M.; Berglund, L.; Reynolds, J. R. Transparent Wood Smart Windows: Polymer Electrochromic Devices Based on PEDOT:PSS Electrodes. ChemSusChem 2018, 11 (5), 854-863. 
(29) Zhang, F.; Yang, X.; Wang, H.; Cheng, M.; Zhao, J.; Sun, L. Structure Engineering of Hole-Conductor Free Perovskite-Based Solar Cells with Low-Temperature-Processed Commercial Carbon Paste As Cathode. ACS Appl. Mater. Interfaces 2014, 6 (18), 1614016146.

(30) Jeon, N. J.; Noh, J. H.; Yang, W. S.; Kim, Y. C.; Ryu, S.; Seo, J.; Seok, S., Il Compositional Engineering of Perovskite Materials for High-Performance Solar Cells. Nature 2015, 517 (7535), 476-480. 